\title{
Taiwanese ELearners' English Language profile and proactive attitude towards unfamiliar English accents
}

\author{
Yuvienco, Janette Custodio $\measuredangle$ \\ National Taiwan University, Taiwan (yuyeni@ntu.edu.tw) \\ Received: 7 September 2019 \\ Revised: 6 January 2020 \\ DOI: $10.5861 /$ ijrse.2020.44019 \\ Accepted: 27 January 2020 \\ ISSN: 2243-7703 \\ Online ISSN: 2243-7711 \\ OPEN ACCESS
}

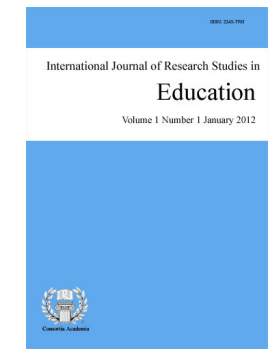

\section{Abstract}

This article schematizes the findings of a research which, in investigating on language learning technologies in second/foreign language education, seeks to identify the relevance of ELearning on the Listening Comprehension of Taiwanese students who enroll in a Freshman English class and prepare themselves to pass a Language Proficiency Test, qualifying them to obtain a Bachelor's degree from the National Taiwan University. Seeking a data-guided empirical approach, this study deploys a dual-purpose research design that combines quantitative sampling and preliminary with pre/post-test; and qualitative research design which deploys Debriefing, a semi-structured process of gathering in written and/or dialogue form the participants' reflections upon their learning experiences through a series of questions that require explanation, analysis and synthesis of their learning tasks, challenges and particular actions in relation to a future second/foreign language learning endeavor. The primary data gathered from this study demonstrate that E-Learning within Blended Learning has varying impact on the Listening Comprehension of Taiwanese E-Learners who have differing degrees of listening proficiency which range from $\mathrm{A}$ to $\mathrm{C}$, where $\mathrm{A}$ is equivalent to $71 \%-96 \%$, B to $43 \%-73 \%$, and $\mathrm{C}$ to $27 \%-42 \%$. Although the findings do not show statistical significant difference in the E-Learners' Listening Comprehension, E-Learning resonates its relevance to proactive Taiwanese E-Learners and their needs of learning support, as it effects positive changes to the Listening Comprehension of advanced E-Learners and negative changes to E-Learners at the beginner's level.

Keywords: e-learning; blended learning; listening comprehension; proactive language learning strategies; Confucian heritage culture; multilingualism; content integrated language learning 


\section{Taiwanese ELearners' English Language profile and proactive attitude towards unfamiliar English accents}

\section{Introduction}

This research project seeks to explore ways of deploying language learning technologies that support Taiwanese freshmen at the National Taiwan University in their effort to improve their Listening Comprehension and pass an English Language Proficiency Test, qualifying them to obtain a Bachelor's degree from the university. In probing into the problem of unfamiliar English accents that face Taiwanese students, this study assumes that Blended Learning, the learners' combined engagement in the use of Information and Communication Technology (ICT)-based learning (hereafter referred to as ELearning) and participating in classroom activities, impacts their Listening Comprehension. Within ELearning the participants are engaged in a full schoolyear of English course in Blended Learning which runs for two terms (i.e., fall and spring semester), each of which consists of two hours of classroom contact and one hour of ELearning during eighteen weeks, totaling to thirty-six hours of training in Listening Comprehension. They watch video-recordings of speakers who speak in varied English accents, that is, General American, Received Pronunciation, Asian-accented English while are engaged in discussions, interviews, reports, and dialogues about topics of General Interest and Specialized Knowledge (e.g., Success, Movies, Creativity, Food, Astronomy, Education, Technology, Climate Change, Culture, Architecture, City, and many others).

In order to systematically gather preliminary data and to allow dialogue with specialists in related fields (e.g., online second/foreign language teachers, curriculum designers, test writers, educational technologists, host administrators, and many others), this paper schematizes the contents and processes of the present research into three headings: Materials and Methods, Results, and Conclusion, Implications and further Research. The Materials and Methods define the relevant concepts and terms that establish the educational and pedagogical setting of the study. It also elucidates the research design which elucidates research questions in relation to a major research project and elaborates the methods of research and tools deployed to gather both quantitative and qualitative data, allowing a data-guided empirical approach to the query: How do Taiwanese ELearners manage failures in developing Listening Comprehension? The Results delineate the preliminary findings of the study derived from the data and their analysis in relation with the major query that seeks to identify related forms of ELearning that support ELearners from Confucian Heritage Cultures. The Conclusion presents in a nutshell the assumptions derived from the analysis of the data and validated by some relevant studies while it delineates the implications on teaching and learning of a second/foreign language and most importantly, illustrates the components and systematic processes of a further study that examines the proactivity of Taiwanese ELearners across year levels.

\section{Materials and methods}

\subsection{Educational and pedagogical setting}

ELearning, as well as other concepts that constitute this study (e.g., Unfamiliar English accents, Taiwanese ELearners, English Language Proficiency Profile, Blended Learning, Listening Comprehension, and many others) has various definitions and ramifications. Upon reviewing the literature, the following sub-section enumerates and defines these terms, to outline the background of the research, to facilitate interdisciplinary understanding among various specialists (e.g., online teachers, curriculum designers, test writers, educational technologists, host administrators, and many others) and to better understand the value of the preliminary findings of this project research in relation to its core inquiry: What forms of e-support address the crisis in second/foreign language learning among Taiwanese ELearners?

60 Consortia Academia Publishing (A partner of Network of Professional Researchers and Educators) 
Taiwanese ELearners' English Language profile and proactive attitude towards unfamiliar English accents

Blended learning - Blended Learning is the learners' combined engagement in Information and Communication Technology-(ICT) based learning materials and classroom activities such as, discussions, games, projects, and many others, with the teacher's facilitation to arrive at a Coherent Learning of a second/foreign language which consists in language learning know-how and knowledge of a specific domain (Yuvienco, 2007, pp. 165-166).

Confucian heritage cultures - Confucian Heritage Cultures is a term that is applied to East Asian students who come from East Asian countries such as China, Korea, Hong Kong, Macau, Japan, and Taiwan, and learners from other counties such as Malaysia, Vietnam, Thailand, Singapore (cf., Thanh, 2014, pp. 30-39), who are known to share the beliefs of Confucius and his heritage.

ELearning - ELearning refers to the online learning platform (or the Online Listening Comprehension Program/OLCP) at the National Taiwan University, which is especially designed for students and teachers of second/foreign language. Since its inception in 2011, it has been deployed in various ways within the Freshman English classes at the university. At the first year of its deployment in the Freshman English class, it was used as an Online Program for extra online learning sessions outside the classroom. Later, between 2012-2015 inclusively, it was used as the source of Information and Communication Technology (ICT)-based environment which offers media and materials for teaching and learning inside and outside the classroom. The underlying principles of the program focus on scaffolded cognitive constructivism, an educational premise which recognizes the capacity of a learner to construct knowledge through, with, and from interaction with the environment (Yuvienco \& Merkelbach, 2010, p. 8).

Complementing the face-to-face teacher's presence in the classroom, which adopts lectures, workshops, and guided language learning, there are three types of use of ELearning which correspond to the teachers' approach to ELearning:

$>$ S-ELearning Mode (supported by ELearning). The ELearning-supported (S-ELearning) deploys ELearning as a form of online learning (or e-learning) outside the classroom.

> G-ELearning Mode (generated by ELearning). The ELearning-generated (G-ELearning) deploys ELearning as a source of media and materials for inside-the-classroom lecture, workshop and/or discussions.

$>$ B-ELearning Mode (based on ELearning). The ELearning-based (B-ELearning) deploys ELearning as the core source of media and materials for teaching and learning inside and outside the classroom.

ELearning and teaching methodology (or Methodik) - Within ELearning, Methodik refers to the approach, classroom organization, and use of media and materials from the perspective of both teachers and learners; it includes both course content and learning objectives (Loo, 2007, p. 78). The approach constitutes the phases and forms of learning; the classroom organization includes the levels, forms of social interaction and lesson plans; and the use of media brings in short films, newspaper articles, case studies, videos and games.

From the Methodik perspective, the methodological characteristics of ELearning may be mapped out as follows:

1) Approach (phases and forms): ELearning is separated into three steps: pre-listening stage, the while-listening stage and the post-listening stage.

$\diamond$ Pre-listening stage uses an introductory text to the video recording to prepare students; it also lists a vocabulary that links to definition and translation of relevant words.

$\diamond$ While-listening stage covers a set of questions in multiple choice and open-ended question formats.

$\diamond$ Post-listening stage uses drag and drop that allows ELearners to complete an outline of the content of 
the video-recording.

2) Classroom organization (levels, forms of social interaction, lesson plans):

$\diamond$ ELearning has three levels: 1 (Basic), 2 (Intermediate), 3 (Advanced)

$\diamond$ It includes eForum where ELearners engage in a discussion about the topic/s in the video-recording.

$\diamond$ It covers two sets of topics during two semesters: The first semester covers a set of topics (a total of 18) on General Interest (e.g. Success, Creativity, Food, and many others); and the second semester (also, a total of 18) on Specialized Knowledge (e.g., Bail-outs, Technology, Medicine, Political Food, and many others).

3) Use of media and other materials:

$\diamond$ ELearning uses video, hyperlink texts, games and vocabulary building application.

$\diamond$ It also offers materials and resources that train reading comprehension.

English language proficiency profile - The English Language Proficiency Profile is determined by calculating the Standard Test Scores (e.g., General English Proficiency Test (GEPT) or the College Admissions Test in English (CAT-E), a set of three examinations taken by Taiwanese students in separate periods before entering the university: (1) The General Scholastic Ability in English (GSAT-E) which is scheduled in the first quarter (February) of the fiscal year, tests students' ability of reading and writing skills in English in a low level of difficulty and gives a full score of 15; (2)Advanced Subjects Test in English (AST-E), which is scheduled in the second quarter (July) of the fiscal year, tests students' ability of reading and writing skills in English in a high level of difficulty, giving a full score of 100 ; (3) Test of English Listening Comprehension (TELC), which is scheduled in the third quarter (October) of the previous fiscal year, tests the students' listening skills and gives a grade of A-C and F, in descending order. Detailed information about each of these Standard Tests is provided by the College Entrance Examination Center.

General English Proficiency Test (GEPT). The General English Proficiency Test (GEPT) is a standardized test of English achievement in the four language skills (listening, speaking, reading, and writing) designed and administered by the Language Training and Testing Center (LTTC). Supported by the Ministry of Education (MOE) of Taiwan, it was recognized in 1991 as a test for selecting prospective students and job applicants. Its development ended in 2002 and most recently, is recognized as a tool that promotes lifelong learning in Taiwan through the study of English as a second/foreign language. Its listening and reading tests give a score of 0-120, while its writing and speaking tests give a score that ranges from 0 to 5. Information about the GEPT may be found at this site: https://www.lttc.ntu.edu.tw/E_LTTC/E_GEPT.htm

General Scholastic Ability Test (GSAT). The General Scholastic Ability English (GSAT-E) tests students' reading and writing skills in two separate sections, accordingly. Compared with the Advanced Subjects Test in English (AST-E), it tests these skills in a lower level of difficulty. Deploying multiple-choice questions, the first section tests vocabulary (use of words and their collocations, which cover 4500 items in the Senior High School English Word-list), rational cloze (understanding of English words, phrases, sentences and paragraphs using context clues), banked cloze (understanding of content words and transitional words using context clues), reading comprehension (comprehending paragraphs with 150-250 words in length using knowledge of English vocabulary, fixed expressions, syntax, and pragmatics as well as analytical skills and deductive reasoning). Deploying constructive response questions, the second section examines students' ability to combine or rewrite sentences based on the prompts given, translate from Chinese to English with correct form and coherent meaning, write a short letter or paragraphs based on a given topic or (a set of) pictures using appropriate vocabulary and sentence structures. It aligns with the 2010 version of the Senior High School Curriculum Guidelines which requires students "to acquire the skills of logical reasoning, critical thinking, and creativity" while learning

62 Consortia Academia Publishing (A partner of Network of Professional Researchers and Educators) 
Taiwanese ELearners' English Language profile and proactive attitude towards unfamiliar English accents

English.

Advanced Subjects Test (AST). The Advanced Subjects Test in English (AST-E) tests students' reading and writing skills in two separate sections, accordingly. Compared with the General Scholastic Ability in English (GSAT-E), it tests these skills in a higher level of difficulty. (The words in italics intend to demonstrate the difference/s.) Deploying multiple-choice questions, the first section tests vocabulary (use of words and their collocations, which cover 7000 items in the Senior High School English Word-list), rational cloze (understanding of English words, phrases, sentences and paragraphs using context clues), banked cloze (understanding of content words and transitional words using context clues), sentence gap fill (ability to understand and organize paragraph structure), reading comprehension (comprehending paragraphs with 200-300 words in length using knowledge of English vocabulary, fixed expressions, syntax, and pragmatics as well as analytical skills and deductive reasoning). Deploying constructive response questions, the second section examines students' ability to translate and write: translate sentences and paragraphs from Chinese to English, and to fill in the blanks in English sentences or paragraphs based on the Chinese given paragraphs, combine or rewrite sentences based on the Chinese-given paragraphs, translate sentences and paragraphs from Chinese to English using advanced English words and constructing complicated sentences (compound, complex, and compound-complex sentence), and write short paragraphs based on a designated topic or topic sentence closely related to students' school and home life in order to evaluate their ability to write descriptive, expository, and narrative paragraphs in English.

Test of English Listening Comprehension (TELC). The Test of English Listening Comprehension (TELC) is a comprehensive assessment of high school students' English listening skills. In line with globalization and international of higher education, the test covers the use of English in everyday life, as well as classroom and other learning-related situations. The TELC scores are used in particular ways by different university departments, as may be specified in the admissions handbook for each plan of application (i.e., through the Stars Program, Personal Application, or Examination and Placement.) They are also used for review and assessment of individual applications, according to the general enrollment regulations. Running for 60 minutes, the TELC consists of 40 test items. It uses multiple-choice questions to assess candidates' ability to understand expressions, sentences, conversations, and short talks. The items are divided into four sections: (1) Picture Description (choosing an appropriate image from the description heard; with single answer and multiple answers), (2) Question-Response (choosing an appropriate reply to question), (3) Short Dialogue (listening to a brief dialogue and answering short questions about it), (4) Short Talks (listening to a brief talk and short answering of questions). The information about each of the three types of test is provided by the College Entrance Examination Center at this website: http://www.ceec.edu.tw/CeecEnglishWeb/E02CEEC.aspx

Unfamiliar English accent - Unfamiliar English Accent is an ELearner's perception of a speaker's way of pronouncing the words of English that is different from one's own, due to country of origin or culture, which adversely affects Listening Comprehension. Without a Model Accent Advantage (Tauroza \& Luk, 1997, p. 58), ELearners do not comprehend English because it is not pronounced in the accent that is used as a model when they are learning the second/foreign language or while living in a culture where they originally belong.

Listening comprehension - Listening comprehension is a process of making sense of five different kinds of knowledge (c.f., Anderson \& Lynch, 1988, p. 3) which include (1) knowledge about the linguistic system of the relevant language, (2) knowledge of the communicative context of the relevant conversation, (3) knowledge of the situation of the conversations (social, physical, and many others), (4) knowledge of text structures and linguistic conventions, (5) knowledge of shared values (factual and socio-cultural knowledge).

Taiwanese ELearners - Taiwanese ELearners are students from Taiwan who engage in ELearning to learn English as a second/foreign language. They go through a process of acquiring a second/foreign language in the light of the knowledge of a subject matter while engaging in determined set of language learning processes and strategies. 


\subsection{Research design}

This section delineates the queries, the methods and tools deployed in the present study to gather both quantitative and qualitative data, allowing a data-guided empirical approach to the study within the Language Teaching Research Framework (Hufeisen, Klippel, \& Sharun, 2009), as it seeks to probe for the first time into the relationship between ELearning and Listening Comprehension.

This study principally probes into how Taiwanese ELearners manage crisis in second/foreign language learning. To arrive at a systematic comprehension of the research, it analyzes the language proficiency of the Taiwanese ELearners, the cause and effect relationship between ELearning and the Taiwanese ELearners' English language proficiency level, and the Taiwanese ELearners' ways of managing unfamiliar English accents. Thus, it queries:

$>\quad$ What is the level of Listening Comprehension of Taiwanese ELearners?

$>\quad$ Does ELearning impact the Listening Comprehension of Taiwanese ELearners?

$>$ Does Unfamiliar English Accent affect Taiwanese ELearners' effort to develop Listening Comprehension? If yes, what do they do?

Seeking a data-guided empirical approach, this study deploys a dual-purpose research design (c.f., Walliman 2005 , p. 294), that is, quantitative sampling and preliminary with pre/post-test, as methods of guaranteeing reliability of the research; and qualitative research design which deploys Debriefing.

(1) Sampling: a primary type of research which involves a single group of participants, this study gathers a group of freshmen $(\mathrm{N}=13)$ at the National Taiwan University which covers $2 \%$ of the total of 742 students, engage in the OLCP and then tested for listening comprehension. The sampling has reading and writing scores in General Scholastic Ability Test (GSAT-E) and Advanced Subjects Test (SAT-E), which reach the bottom 10\%; yet, their scores in the Test of Listening Comprehension (TELC) vary between $\mathrm{A}$ and $\mathrm{C}$, where $\mathrm{A}$ is the highest grade. The observations are carried out only after the experiment without any control or check.

(2) Preliminary with pre/post-test (or Test-retest reliability): involving a research with check and control, this study includes a group of students from various colleges of National Taiwan University (i.e., the Colleges of Medicine, Management/Life Science, and Bio-resources and Agriculture; and Engineering) who are tested for listening using the General English Proficiency Test (GEPT) before engaging in ELearning. After, it is tested again after engaging in a 36-hour session of ELearning and the results are compared.

(3) Debriefing is a semi-structured process of gathering in written and/or dialogue form the participants' reflections upon their learning experiences through a series of questions that require explanation, analysis and synthesis of their learning tasks, challenges and particular actions in relation to a future second/foreign language learning endeavor; it uncovers data which are not so much what the ELearners' successes and failures are, as the whys of their e-learning condition. It consists of two parts: (1) a dialogue between the teacher/facilitator and the ELearners, alone or in small groups, about the their ELearning experiences inasmuch as they relate with either or both of the reported Standard Test scores (e.g., GEPT, AST-E, GSAT-E, TELC, and many others) and/or responses to some other relevant questionnaire/s (e.g., Strategy Inventory of Language Learning (SILL), Proactive Language Learning Strategies (PLLS), and many others); (2) a self-written account of the ELearners' answers to the questions that guide Debriefing:

$\diamond$ What caused the positive/ negative results? 
$\diamond$ How did you react to them?

$\diamond$ What opportunities/ difficulties did you encounter?

$\diamond$ What should you start, stop, continue doing?

To determine the predictive validity of the research, this longitudinal study adopts the result of a previous study that identifies the correlation between listening comprehension and language learning strategies by deploying GEPT and the Strategy Inventory of Language Learning (SILL, version 7.0) (Oxford, 1990), which states that listening comprehension correlates with language learning strategies at .01674 under $95 \%$ of certainty where the values are significant at the $p<.05$ level (with $d f=80$ ).

\section{Results of data analysis}

To recall, the present study seeks to explore ways to improve the Listening Comprehension of Taiwanese ELearners at the National Taiwan University in order to support them in their efforts to pass the required English Language Proficiency Level on their second year or before they graduate. In this regard, the study firstly probes into the levels of Listening Comprehension of Taiwanese ELearners $(\mathrm{N}=37)$ then, it examines the impact of ELearning on their Listening Comprehension, finally, it looks into their actions and reactions to ELearning challenges specifically, unfamiliar English accents. In view of the aforementioned queries, the present paper reports the following findings:

(1) The levels of Listening Comprehension of Taiwanese ELearners vary from A-C: A level (Advanced) ELearners have the lowest score of 88 and the highest of 109; B level (Intermediate) ELearners have the lowest score of 62 and the highest of 87; C Level (Beginning) ELearners have the lowest score of 37 and the highest of 61 .

(2) ELearning leads to either an increase or decrease of GEPT listening scores, showing varying learning effect on ELearners in A, B and C levels whose Significant Range of Difference (SRD) stretches between -13 and +6 . (Where the SRD value is within the hypothetical range of -10 and +10 inclusively, it claims that the intervention exerts an effect on learning.). Yet, ELearning does not yield a Statistical Significant Difference on listening comprehension, that is, $p=.38$ under $p$ value of .05 .

(3) Unfamiliar English accents interfere with Taiwanese ELearners' efforts in developing Listening Comprehension yet, they cope with the challenge positively, revealing their underlying proactive attitudes towards second/foreign language learning: receptivity, adaptability, and determination.

\subsection{English language proficiency profile of Taiwanese ELearners}

An analysis of the participants' scores in the College Admissions Test in English shows that the highest score of listening of Taiwanese ELearners is 109 and the lowest score is 37: 16\% of Taiwanese ELearners, who have a General Scholastic Ability Test (GSAT-E) score between 10 and 12 and an Advanced Subjects Test (AST-E) score between 81.00 and 82.50 , belong to the A level of language proficiency with the lowest score of 88 and the highest of 109 in GEPT listening. Also, 66\% of Taiwanese ELearners, who have a General Scholastic Ability Test (GSAT-E) score between 8 and 9 and an Advanced Subjects Test (AST-E) score between 59.00 and 80.00 , belong to the B level of language proficiency with the lowest score of 53 and the highest of 88 in GEPT listening. Lastly, $16 \%$ of Taiwanese ELearners, who have a General Scholastic Ability Test (GSAT-E) score between 6 and 7 and an Advanced Subjects Test (AST-E) score between 45.00 and 58.00, belong to the C level of language proficiency with the lowest score of 37 and the highest of 61 in GEPT listening.

The data indicate that the English Language Proficiency Profile of Taiwanese ELearners is as follows: The Listening Comprehension of Taiwanese ELearners in their freshman year ranges between 37 and 109, where $\mathrm{C}=$ $37-61(31 \%-51 \%) ; \mathrm{B}=62-87(52-73 \%) ; \mathrm{A}=88-109(74 \%-91 \%)$. Their reading and writing skills in General 
Information (GSAT-E) range between 6-12 (40\%-80\%), where $\mathrm{C}=6-7(40 \%-46 \%) ; \mathrm{B}=8-9(53 \%-60 \%) ; \mathrm{A}=$ 10-12 (66\%-80\%). Also, their reading and writing skills in Specialized Knowledge (AST-E) range between 45-83, where $\mathrm{C}=45 \%-58 \% ; \mathrm{B}=59-80 ; \mathrm{A}=88-109$. Generally, the profile demonstrates a set of language learning experience which results to reading and writing skills that are lower in General Information than in the Specialized Knowledge at all levels. Yet, the learning experience in listening comprehension results in the lowest score in all levels and reaches the highest score in the highest level. The Taiwanese ELearners' learning experience is predominantly visual and kinesthetic (or the manual doing of something which allows to master lasting conceptions, for instance, through writing) yet, falls short of auditory input.

\subsection{Impact of ELearning on listening comprehension}

The impact of ELearning on Listening Comprehension is measured by probing into the Significant Range of Difference (SRD) and the Statistical Significant Difference (SSD). An analysis of the SRD of ELearning or the Gain/Loss Scores on the ELearners' Listening Comprehension shows varying changes in ELearners in A, B and C levels, stretching from -13 to +6 . The Significant Range of Difference is as follows: $16 \%$ of ELearners, who belong to the A level with a pre-GEPT score between 88 and 109 (74\%-91\%), obtain a post-test score between 85 and 115 (71-96\%); their lowest score decreased by three points and the highest score increased by six points. $66 \%$ of ELearners, who belong to the B level with a pre-GEPT score between 53 and 88 (44\%-73\%), obtain a post-test score between 51 and 93 (43\%-78\%); their lowest score decreased by two points and the highest score increased by five points. Finally, $16 \%$ of ELearners, who belong to the C level and with a pre-GEPT score between 37 and $61(31 \%-61 \%)$, obtain a post-test score between 32 and $48(27 \%-40 \%)$; their lowest score decreased by five points and the highest score decreased by thirteen points. (The SRD is calculated by subtracting the difference of mean between the pre and post-test values; if the SRD value is within the hypothetical range of -10 and +10 inclusively, it claims that the intervention exerts an impact on the learning process).

The aforementioned data show that the impact of ELearning on the Listening Comprehension of the ELearners on the A-level ELearners and C-level ELearners vary, which may be caused by a difference of mindsets among them: A-level ELearners are fast second/foreign language learners who are able to easily shift from traditional to ICT-based forms of learning, while C-level ELearners are slow who, with hard-and-fast modes of behaviouristic learning, are fixated with their unresolved challenges to learn a second/foreign language, demonstrating a dwindling of interest in ELearning which may border on demotivation.

Meanwhile, analyzing the Statistical Significant Difference (SSD) between the GEPT test scores at the beginning (the mean of which is 72) and at the end (the mean of which is 69) of the ELearning course, the results yield 0.39 , a value that is bigger than the set $\mathrm{p}$ value of .05 as the cut-off for significance thus, demonstrating a lack of significant difference. (If the p-value is less than .05 , we reject the null hypothesis that there's no difference between the means and conclude that a significant difference does exist under 0.5 and likely to generalize to the broader population of interest.) It demonstrates that there is no measurable difference between the pre and the post scores of the listening, and that the $40 \%$ probability of obtaining that difference by chance is large. This may be due to a mismatch of the target learning in ELearning and the listening comprehension tested in the GEPT. ELearning focuses on five different aspects of Listening Comprehension such as knowledge about the linguistic system of the relevant language, knowledge of the communicative context of the relevant conversation, knowledge of the situation of the conversations (social, physical, and many others), knowledge of text structures and linguistic conventions, and knowledge of shared values (factual and socio-cultural knowledge) (c.f, Section 2.1.7) while GEPT, on the use of basic English to communicate about topics in daily. Specifically, the listening skill covers the understanding of general English conversations in daily life situations and the general meaning of announcements, advertisements, and broadcasts, while the reading skill, the ability to read stories and news articles on familiar or concrete topics and personal letters (c.f., https://www.lttc.ntu.edu.tw/e_lttc/E_GEPT/intermediate.htm). 
Taiwanese ELearners' English Language profile and proactive attitude towards unfamiliar English accents

3.3 Proactive attitude towards unfamiliar English accents

Upon analysis of the data derived from Debriefing, which seeks to gather the whys of the Taiwanese ELearners' learning condition, the observations are:

(1) Primary challenges that arise among Taiwanese ELearners include unfamiliar English accents, speed of speech, vocabulary which ranges from local and specialized terms/proper names, and topics which include a variety of unacquainted professional knowledge.

(2) Unfamiliar English accents interrupt the learners' efforts to develop Listening Comprehension yet, to overcome this and similar difficulties, the Taiwanese ELearners strive to deploy various strategies and techniques (e.g. do more practice, guess the speaker's meaning, memorize more vocabulary, use one's reading skills to train listening comprehension, and many others) which reveal positive attitudes such as, receptivity, adaptability, and determination. Rooted in proactivity, these are expressed in the following statements:

$\diamond$ Responsibility: Even if am not good in English, I try to do what the teacher requires us to do inside and outside of class; I am attentive in class: I do vocabulary building, I learn how to focus on key ideas.

$\diamond$ Adaptability: At the start, I was unfamiliar and feeling uneasy with the method of Elearning, as I did not like the feeling of getting low scores, but I forced myself to do every unit in ELearning.

$\diamond$ Determination: I want to prove that I can do better than one exam's failing score; I consistently exert effort in completing the ELearning tasks; I do test practice when I feel lazy to study.

Similar to Tauroza and Luk's (1997, pp. 64-66) assumption, which recognizes that Unfamiliar English Accent interferes with listening comprehension, the research data show that unfamiliar English accent brings particular difficulties to Taiwanese ELearners. Yet, a proactive attitude sustains their efforts to engage in listening, which corroborates what Major, Fitzmaurice, Bunta, and Balasubramanian (2002, p. 187) speculate about the role of positive attitude in increasing Listening Comprehension. It reflects the proactive autonomy (Littlewood, 1999, pp. 75-76) which enables ELearners to take charge of their own learning, determine their objectives, select methods and techniques, and evaluate what has been acquired. It also reveals the role of emotions and their dynamics among Taiwanese Elearners who are exposed to Multilingualism (Cenox, 2013, p. 9).

\section{Conclusions, implications and recommendations}

\subsection{Conclusions}

Probing into the relationship between ELearning and Taiwanese ELearners' Listening Comprehension, the study shows that ELearning does not significantly impact Listening Comprehension, and Taiwanese Elearners' at the beginning level are affected adversely by the experience yet, advanced Taiwanese ELearners profit from engaging in ELearning. This demonstrates that ELearning, which consists in the Methodik Approach of second/foreign language learning (Loo, 2007, p. 78) admits Taiwanese ELearners' inability to tackle unfamiliar English accents yet, it recognizes and supports the ELearners' proactive dispositions such as, responsibility, adaptability and determination, and these are deemed to have repercussions on success in one's learning and future career.

Applied linguistics defines learner autonomy as "taking responsibility for their own learning, being able to control their own learning and perceiving that their learning successes and failures are to be attributed to their own efforts and strategies, rather to factors outside their control" (Dickinson, 1995, pp. 173-174). It reveals the 
learner's acceptance of responsibility for his or her learning which is reflected in the following actions: goal-setting, seeking materials and methods of learning, evaluation not only in relation to one's personal goal, but also to the demands of society.

Also, proactive personality is related to career adaptability which allows individuals to be more successful in their career, adapting more readily to their environment. Proactive individuals are more likely than are non-proactive individuals to have initiated preparation to cope with career-related changes, to identify promotion opportunities, and to create a work environment that conforms to career needs. This proactive socialization behavior in the workplace, according to Wanberg and Kammeyer-Mueller (2000, p. 373), enables them to make sense in a new environment --by seeking information, asking feedback, building relationship and framing events positively during times of stress- to gradually learn how things are done and contribute effectively in their job.

The results, which are derived from a longitudinal study, indicate a significant contribution to understanding the value of proactivity within ELearning. An enduring individual trait which cannot simply be confined to a contextual domain such as, the workplace (Parker, Williams, \& Turner, 2006, p. 637), proactivity points to a disposition that expresses autonomy which is manifested in self-regulation. Autonomy moves towards change primarily with oneself yet, more importantly with a significant an "other', i.e. a teacher, who extends the learners' acts and activities beyond one's present capacities. Such reality suggests Ryan and Deci's theory of self-determination (2017) where the principle of autonomy, which is true regulation (Ryan \& Deci, 2006, p. 1583), fastens closely with Little's theoretical considerations of social interaction. Within ELearning, ELearners start from learning by themselves; and while moving toward their end, they are guided, facilitated and supported by a teacher, from whom they receive and respond to various orientations and directives; the absence of adequate guidance, facilitation and support from the teacher (or a facilitator) renders learner autonomy within Blended Learning static and inactive.

\subsection{Implications for use in second/foreign language teaching}

The results of the present longitudinal study relate with four implications for use in second/foreign language teaching, as follows:

Blended Learning that constitutes ELearning entails that teachers arrange Debriefing, a form of an individual or small group dialogue with ELearners that gather their reflections upon their learning experiences and feed upon the teacher's understanding of the ELearners' learning styles and strategies. (According to Ehrman, Leaver, and Oxford (cf., 2003, pp. 314-315), learning styles may be the general approaches that students use in acquiring a new language or in learning any other subject in relation to one's personality; and learning strategies are the specific actions that students take as one's personal set of tools and resources for active, deliberate, and purposeful self-regulation of learning.) During the dialogue, the teacher also offers ELearners the guidance and support "in their language learning and help them find the most effective and efficient way of doing so in a variety of learning environments (i.e., from the classroom to online to learning in self-access centres) (Mozzon-McPherson, 2002).

ELearning, which offers a variety of tasks that range from reading a summary, managing vocabulary, engaging in e-forum, answering multiple choice/open-ended questions and drafting an outline, may require more focused sets of practice for ELearners at the beginner level who, while inadvertently unfamiliar with learning strategies that correspond with the required tasks, easily fail to match them with their habituated learning style.

ELearners, who have varying levels of English proficiency in listening comprehension which ranges from $31 \%$ to $91 \%$, need a complementary training in reading comprehension. ELearning, which collectively trains listening and reading comprehension, transcends the classroom training of listening and speaking that seeks to support good language habits done through "pattern drills, memorization of dialogues or choral repetition of structural patterns" (Williams \& Burden, 1997, p. 8) of the Audio-lingual Approach. It also goes beyond the training in reading that focuses on internal learning mechanisms --how the human mind receives, processes, 
Taiwanese ELearners' English Language profile and proactive attitude towards unfamiliar English accents

stores and retrieves information - and are believed to be used for learning in general, not just language learning alone (Lightbown \& Spada, 2013, p. 214) of the Cognitive Approach. ELearning is a combined training in the passive skills of listening and reading that supports ELearners' proactive personality to continuously learn the active skills of writing and speaking about General and Specialized Knowledge.

ELearners in the beginning level, who are adversely affected by ELearning, as they use strategies in a random, unconnected, and uncontrolled manner, may need to be led, guided and supported to carefully orchestrate strategies, targeted in a relevant and systematic way while completing specific L2 tasks by raising their awareness of the learning pattern embedded in ELearning which may serve as a personal form of learning within Blended second/foreign Language Teaching.

\subsection{Recommendation for further research}

Within the aforementioned Foreign Language Teaching Framework, this section delineates the appropriacy of an Actual Experimental Research Design (cf., Walliman, 2005, p. 294) which deploys Paired Post-test Only Control Group to arrive at a continuous development of ELearning as a language learning technology that helps Taiwanese non-freshmen at the National Taiwan University to improve their second/foreign language learning skills and to prepare them to pass an English Language Proficiency Test. The design examines the proactivity level of Taiwanese ELearners across year levels at the National Taiwan University where they train not only for Listening Comprehension, but also for Reading Comprehension. In this particular design, a pair of e-learners from two different groups is selected: one has engages in developing Listening and Reading comprehension in ELearning, or a variant of it or its combination, and the other has reading in an Online English Program, the e-learning component of which is acquired from a third party. Both are tested for proactive language learning strategies at the end of the intervention, and the results are compared. The components and processes of a future study are illustrated in the following sections:

Scope and scheme - The participants are Taiwanese ELearners in their non-freshman levels (i.e., sophomore, junior, and senior levels) with diverse levels of English Language proficiency, who complete an eighteen-week semester of Online English Program at National Taiwan University. They engage in an English course which has three phases of classroom- learning contact of 28 hours and ELearning (or its variant) with a minimum of 18 hours totaling to 46 hours. Each phase constitutes six weeks, where the last week of each phase tests Listening and Reading Comprehension, totaling to three Periodic Tests.

Data and hypothesis - It has been established that Taiwanese ELearners have varying levels of language proficiency: Their percentile scores in reading and writing skills in General Information range from $40 \%-80 \%$; in Specialized Knowledge, 45\%-83\%; and in Listening Comprehension, 27\%-42\%. Also, it is known that the Taiwanese ELearners are proactive, as shown in their capacity to be receptive, adaptable, and determined. Yet, the impact of ELearning on Listening Comprehension is inconclusive. Similarly, the level of proactivity of Taiwanese ELearners in varying year levels is undefined. Nonetheless, the proactive language learning strategies that the Taiwanese ELearners deploy in developing Listening Comprehension may be the same set of strategies used in reading comprehension. It is, therefore, hypothesized that: There will be no significant difference in the extent that Taiwanese ELearners deploy proactive language learning strategies while training for Listening/ Reading Comprehension within ELearning or a variant of it.

Queries and tools - In view of exploring the features of e-learning support to Taiwanese ELearners, it is systematic to identify the ELearner's second/foreign language and year level in order to examine whether engaging in an ELearning-related online learning program, for example, ELearning for Listening and Reading Comprehension, impact ELearners' proactive language learning strategies, yielding statistical significant difference. The following are relevant research questions that seek to gather both descriptive and prescriptive data:

Does an ELearning-related program (e.g., ELearning for Listening/Reading Comprehension) support 
Taiwanese ELearners in non-freshman year?

$>\quad$ What is the level of proactivity of Taiwanese ELearners in non-freshman year? Does the level of proactivity of Taiwanese ELearners in non-freshman year change after engaging in ELearning for Listening/Reading Comprehension?

$>\quad$ How many hours of ELearning prepare Taiwanese ELearners in non-freshman year for the A-level Online Listening/Reading Comprehension Test?

In line with the aforementioned questions, the appropriate tools that gather relevant data from participants while addressing data/method-triangulation are the Computerized-Adaptive Testing, Proactive Language Learning Strategies Scale and Debriefing. The Computerized-Adaptive Testing (CAT) is an alternative to "one-size-fits-all" standardized tests which helps to identify a student's learning level more precisely than fixed-question exams, especially for students at the lower and higher ends of the learning spectrum. The Proactive Language Learning Strategies Scale (PL2S2) is a measurement tool which gathers information about the ELearners' proactivity and their awareness of use of second/foreign language learning strategies. It combines items of the Proactive Personality Scale (or PPS) which quantifies the disposition of individuals toward "identifying opportunities for constructive change, showing initiative and taking action, and persevering until change is affected" (Bateman \& Crant, 1993, p. 108) and the Strategy Inventory Language Learning (SILL) (Oxford, 1990) which determines the ways and their varying degrees of learning a second/foreign language according to six major categories such as cognitive, metacognitive, memory-related, compensatory, affective and social. Debriefing is a semi-structured process of gathering in written and/or dialogue form the participants' reflections upon their learning experiences through a series of questions that require explanation, analysis and synthesis of their learning tasks, challenges and particular actions in relation to a future second/foreign language learning endeavor. These tools combine the qualitative and quantitative methods and techniques that meet the needs of a data/method-triangulated research into the guidelines and policies that direct ELearning to provide support to Taiwanese ELearners' efforts in developing Listening and Reading Comprehension.

Acknowledgements - Part of this paper was presented with the title Taiwanese Students and their Perceptions of Unfamiliar English Accents within ELearning at the 23rd Conference International Association for World Englishes (IAWE) on 2018 May 31-June 2 at the Ateneo de Manila University, Quezon City, Philippines.

\section{References}

Anderson, A., \& Lynch, T. (1988). Listening. Oxford University Press.

Bateman, T. S., \& Crant, J. M. (1993). The proactive component of organizational behavior: A measure and correlates. Journal of Organizational Behaviour, 14, 103-118. https://doi.org/10.1002/job.4030140202

Brown, H. D. (2001). Teaching by principles: An interactive approach to language pedagogy. Longman.

Cenoz, J. (2013). Defining multilingualism. Annual Review of Applied Linguistics, 33, 3-18. https://doi:10.1017/S026719051300007X

Dickinson, L. (1995). Autonomy and motivation: A literature review. System, 23(2), 165-174. https://doi.org/10.1016/0346-251X(95)00005-5

Ehrman, M. E., Leaver, B. L., \& Oxford, R. L. (2003). A brief overview of individual differences in second language learning. System, 31, 313-330. https://doi.org/10.1016/S0346-251X(03)00045-9

Hufeisen, F., Klippel, J., \& Sharun, F. (2009). Methoden der sprachlehrforschung [Methods of research in language teaching]. Germany: Technische Universitaet Darmstadt.

Lightbown, P., \& Spada, N. (1999). How languages are learned. Oxford University Press.

Little, D. (2000). Learner autonomy and human interdependence: Some theoretical and practical consequences of a social-interactive view of cognition, learning and language. In B. Sinclair, I. McGrath \& T. Lamb

70 Consortia Academia Publishing (A partner of Network of Professional Researchers and Educators) 
Taiwanese ELearners' English Language profile and proactive attitude towards unfamiliar English accents

(Eds.), Learner autonomy, teacher autonomy: Future directions (pp. 15-23). Longman/Pearson Education.

Littlewood, W. (1999). Defining and developing autonomy in East Asian contexts. Applied Linguistics, 20(1),

71-94. https://doi.org/10.1093/applin/20.1.71

Loo, A. (2007). Teaching and learning modern languages in large classes. Shaker-Verlag.

Major, R. C., Fitzmaurice, S. F., Bunta, F., \& Balasubramanian, C. (2002). The Effects of nonnative accents on listening comprehension: Implications for ESL Assessment. TESOL Quarterly, 36, 173-190. https://doi.org/10.2307/3588329

Mozzon-McPherson, M. (2002). Language advising. Centre for Languages, Linguistics and Area Studies. Retrieved from https://www.llas.ac.uk/resources/gpg/93.html\#toc_2

Oxford, R. L. (1990). Language learning strategies: What every teacher should know. Heinle \& Heinle Publishers.

Parker, S. K., Williams, H. M., \& Turner, N. (2006). Modeling the antecedents of proactive behavior at work. Journal of Applied Psychology, 91(3), 636-652. https://doi.org/10.1037/0021-9010.91.3.636

Ryan, R. M., \& Deci, E. L. (2006). Self-regulation and the problem of human autonomy: Does psychology need choice, self-Determination, and will? Journal of Personality, 74(6), 1557-1586. https://doi.org/10.1111/j.1467-6494.2006.00420.x

Ryan, R. M., \& Deci, E. L. (2017). Self-determination theory: Basic psychological needs in motivation, development, and wellness. The Guilford Press.

Tauroza, S., \& Luk, J. (1997). Accent and second language listening comprehension. RELC Journal, 28, 54-71. https://doi.org/10.1177/003368829702800104

Than, P. (2014). Implementing cross-culture pedagogies: Cooperative learning at Confucian heritage cultures. Singapore: Springer. https://doi.org/10.1007/978-981-4451-91-8

Walliman, N. S. R. (2005). Your research project: A step-by-step guide for the first-time researcher (2nd ed.). Thousand Oaks, CA: Sage Publications.

Wanberg, C. R., \& Kammeyer-Mueller, J. D. (2000). Predictors and outcomes of proactivity in the socialization process. Journal of Applied Psychology, 85(3), 373-385. https://doi.org/10.1037/0021-9010.85.3.373

Williams, M., \& Burden, R. L. (1997). Psychology for language teachers: A social constructivist approach. Cambridge University Press.

Yuvienco, J. C. (2007). An educational framework for blended learning within foreign language education. In C. Merkelbach (Ed.), Gemischte Lehr- und Lernformen in Fremdsprachenunterricht [Mixed forms of teaching and learning within foreign language teaching] (pp. 61-184). Shaker Verlag.

Yuvienco, J. C., \& Merkelbach, C. (2010). Affordances and sequence for an IT-based listening comprehension program. Tapestries, 4, 1-13. 


\section{Appendix}

This section contains key information in a tabulated form for a more reader-friendly access of the primary data gathered from this study.

\section{Table 1}

College Admissions Test in English in Taiwan

\begin{tabular}{lccc}
\hline \multicolumn{1}{c}{ Components } & GSAT-E & AST-E & TELC \\
\hline Time Administered & February & August & October of previous year \\
Target Skills & Reading \& Writing & Reading \& Writing & Listening \\
Highest Score & 15 & 100 & A \\
No. of Items & $56(+2$ big items $)$ & $51(+2$ big items $)$ & 40 \\
Duration & 100 mins & $80 \mathrm{mins}$ & $60 \mathrm{mins}$ \\
\hline
\end{tabular}

Table 2

English Language Proficiency Profile of Taiwanese ELearners (N=37)

\begin{tabular}{ccccccc}
\hline $\begin{array}{c}\text { Listening } \\
\text { Grade }\end{array}$ & $\begin{array}{c}\text { No. of } \\
\text { Students }\end{array}$ & Percentage $\%$ & $\begin{array}{c}\text { GSAT-E } \% \\
\text { Reading \& } \\
\text { Writing }\end{array}$ & $\begin{array}{c}\text { AST-E \% } \\
\text { Reading \& Writing }\end{array}$ & \multicolumn{2}{c}{$\begin{array}{c}\text { Pre-GEPT \% } \\
\text { Listening }\end{array}$} \\
\hline A & 6 & 16 & $10-12(66-80)$ & $81.00-82.50$ & $88(73)$ & $109(91)$ \\
B & 25 & 66 & $8-9(53-60)$ & $59.00-80.00$ & $62(52)$ & $87(73)$ \\
C & 6 & 16 & $6-7(40-46)$ & $45.00-58.00$ & $37(31)$ & $61(51)$ \\
\hline
\end{tabular}

Table 3

Significant Range of Difference of Listening Comprehension Across levels $(v=+6 /-13)(N=37)$

\begin{tabular}{ccccccccc}
\hline \multirow{2}{*}{$\begin{array}{c}\text { Listening } \\
\text { Grade }\end{array}$} & $\begin{array}{c}\text { No. of } \\
\text { Students }\end{array}$ & Percentage $\%$ & \multicolumn{2}{c}{$\begin{array}{c}\text { Pre-GEPT } \\
\text { Listening }\end{array}$} & \multicolumn{2}{c}{$\begin{array}{c}\text { Post-GEPT } \\
\text { Listening }\end{array}$} & \multicolumn{2}{c}{$\begin{array}{c}\text { Significant Range of } \\
\text { Difference }\end{array}$} \\
\cline { 4 - 8 } & & & Low & High & Low & High & Low & High \\
\hline A & 6 & 16 & 88 & $\mathbf{1 0 9}$ & 85 & $\mathbf{1 1 5}$ & -3 & 6 \\
B & 25 & 66 & 53 & 88 & 51 & 93 & -2 & 5 \\
C & 6 & 16 & $\mathbf{3 7}$ & 61 & $\mathbf{3 2}$ & 48 & -5 & -13 \\
\hline
\end{tabular}

\section{Table 4}

Taiwanese ELearners' English Language Proficiency Profile

\begin{tabular}{cccc}
\hline Listening & (GSAT-E) & $($ AST-E) & GEPT Listening Score \\
Level & Reading \& Writing & Reading \& Writing & $85-\mathbf{1 1 5}$ \\
\hline A & $10-12$ & $81.00-82.50$ & $51-84$ \\
B & $9-8$ & $59.00-80.00$ & $\mathbf{3 2 - 5 0}$ \\
C & $7-6$ & $45.00-58.00$ & \\
\hline
\end{tabular}

